Disclosure of Interests: Caitrin Coffey: None declared, Avneek Singh Sandhu: None declared, Cynthia S. Crowson: None declared, Dennis Asante: None declared, Eric Matteson Grant/research support from: Eric Matteson has received research grants from Pfizer and Sun Pharmaceutical Industries, Ltd. for work on the pathobiology of rheumatoid arthritis. Consultant for: Eric Matteson has received consultancy fees from Boehringer Ingelheim for an advisory board., Thomas G. Osborn: None declared, Kenneth J Warrington : None declared, Ashima Makol: None declaredDOI: 10.1136/annrheumdis-2019-eular.5073

\section{AB0647 ASSOCIATION OF VASCULAR BIOMARKERS WITH SYSTEMIC SCLEROSIS CLINICAL FEATURES AND NAILFOLD VIDEOCAPILLAROSCOPY ALTERATIONS- CROSS SECTIONAL STUDY}

Jelena Colic ${ }^{1}$, Aleksandra Antovic ${ }^{2}$, Quan Tang ${ }^{2}$, Maja Zlatanovic ${ }^{1}$, Slavica PavlovDolijanovic $^{1}$, Ivica Jeremic ${ }^{1}$, Aleksandra Kadic ${ }^{1}$, Karin Gunnarsson ${ }^{2}$, Annika Nordin ${ }^{2}$, Jelena Vojinovic ${ }^{3}$, Mirjana Sefik Bukilica ${ }^{1}$, Nemanja Damjanov ${ }^{1}$. ${ }^{1}$ University of Belgrade, School of Medicine, Institute of Rheumatology, Belgrade, Serbia; ${ }^{2}$ Karolinska Institutet, Department of medicine, Rheumatology Unit, Stockhom, Sweden; ${ }^{3}$ University of Nis, Faculty of Medicine, Nis, Serbia

Background: The most reliable markers reflecting endothelial activation and injury in Systemic sclerosis (SSc), are intercellular adhesion molecule (ICAM1), vascular cell adhesion molecule (VCAM1), E selectin (Es) and $\mathrm{P}$ selectin (Ps) (1)

Objectives: To assess concentrations of these vascular biomarkers in SSc patients (pts) in comparison to healthy controls ( $\mathrm{HC}$ ) and in relation to disease manifestations.

Methods: Patients who fulfilled the 2013 ACR/EULAR SSc classification criteria and have never been treated with endothelin receptor antagonist, phosphodiesterase 5 inhibitors or prostanoids were eligibile. Exclusion criteria were overlap syndromes, other autoimmune and cardiovascular diseases, diabetes mellitus, thrombosis, pregnancy, active infection or neoplastic diseases. Our study included 53 SSc pts [34 limited (IcSSc) and 19 diffuse cutaneous SSc (dcSSc)] and 31 age- and sex matched HC. Serum concentration of ICAM1, VCAM1, Es and Ps were measured using a commercial ELISA kit (Quantikine; R\&D Systems), expressed as $\mathrm{ng} / \mathrm{mL}$. Clinical evaluation of patients was obtained, including nailfold videocapillaroscopy (NVC). Disease activity was assessed by the revised EUSTAR activity index. Statistical analysis was done in R. Student's t-test or ANOVA, otherwise Mann-Whitney U or Kruskal-Wallis tests were used. Pearson's or Spearman's correlation were done depends on nature of data. ICAM1 cut off value were assessed with ROC analysis. Association were performed with univariate logistic regression for NVC alterations and multivariate for Anti-Topol/ Scl70 antibodies (aTSa).

Results: Concentration of all markers were elevated in SSc pts compared to HC (ICAM1 $p<0.001$, VCAM1 $p<0.001$, Es $p<0.05$, Ps $p>0.05$ ). Different disease subsets exhibited higher values of ICAM1 and VCAM1 respect to $\mathrm{HC}$ (ISSc $\mathrm{p}<0.05$, dSSc $\mathrm{p}<0.001)$. Concentration of ICAM1 was higher in dcSSc compared to IcSSc $(\mathrm{p}<0.05)$. ICAM1 level were independently associated with positive aTSa (OR 1.2, 95\% Cl 1.02-1.35, $\mathrm{p}<0.001$ ), with distinguishing cut off value of 34.94 (Sn $0.90 \%$, Sp $0.60 \%$, AUC 0.85). ICAM 1 was positively correlated with the erythrocyte sedimentation rate $(r \quad 0.3, p<0.05)$ especially within disease duration $>3$ years group $(r$ 0.4, $p<0.05)$. Higher levels of ICAM1 was found in diffusing capacity of the lungs for carbon monoxide $<70 \% \quad(p<0.05)$, modified Rodnan skin score $>14 \quad(p<0.05)$ and active disease $(p<0.05)$ group. Calcinosis group had decreased level of Es $(p<0.05)$ and increased Ps $(p<0.05)$. Es was lower in group with acroosteolysis $(p<0.05)$. Trends towards increasing markers concentration from early to late NVC pattern were observed for all biomarkers except Es which showed the highest concentration in active group, but without significant differences $(p>0.05)$. Few megacapilaries were associated with ICAM1 (OR 1.2, 95\% Cl 1.06$1.34, \mathrm{p}<0.05)$ and $\mathrm{Ps}(\mathrm{OR} 1.2,95 \% \mathrm{Cl} 1.08-1.39, \mathrm{p}<0.05)$, while presence of bushy capillaries were associated with ICAM1 (OR $1.3,95 \% \mathrm{Cl}$ $1.06-1.36, p<0.05)$ level.

Conclusion: Our results support the role of vascular biomarkers in SSC pathogenesis. Besides anti-Topol/Scl70 antibodies, ICAM-1 could be used as an additional marker of dSSc. Elevation of ICAM1 and PS concentration might be associated with late NVC alterations.

\section{REFERENCES}

[1] Mostmans Y, Cutolo M, Giddelo C, et al. The role of endothelial cells in the vasculopathy of systemic sclerosis: A systematic review. Autoimmun Rev 2017;16:774-86. doi:10.1016/.autrev.2017.05.024
Disclosure of Interests: Jelena Colic: None declared, Aleksandra Antovic: None declared, Quan Tang: None declared, Maja Zlatanovic: None declared, Slavica Pavlov-Dolijanovic: None declared, Ivica Jeremic: None declared, Aleksandra Kadic: None declared, Karin Gunnarsson: None declared, Annika Nordin: None declared, Jelena Vojinovic: None declared Mirjana Sefik Bukilica: None declared, Nemanja Damjanov Grant/research support from: AbbVie, Pfizer and Roche, Consultant for: Abbvie, Gedeon Richter, Merck, Novartis, Pfizer and Roche., Speakers bureau: Abbvie, Gedeon Richter, Merck, Novartis, Pfizer and Roche. DOI: 10.1136/annrheumdis-2019-eular.7903

\section{AB0648 CORRELATIONS BETWEEN NEUTROPHIL/ LYMPHOCYTE RATIO AND CLINICAL CHARACTERISTICS OF PATIENTS WITH SYSTEMIC SCLEROSIS}

Giovanna Cuomo ${ }^{1}$, Francesco Masini ${ }^{2}$, Klodian Gjeloshi $^{2}$, Francesco Guarino ${ }^{2}$ Fiammetta Danzo ${ }^{2}$, Luigi Elio Adinolfi' ${ }^{2}$, Ciro Romano ${ }^{2} .{ }^{1}$ University of Campania Luigi Vanvitelli, Medicina di precisione, Caserta, Italy, ${ }^{2}$ University of Campania Luigi Vanvitelli, Department of Medical and Surgical Sciences, Caserta, Italy

Background: The ratio of neutrophils to lymphocytes (NRL) is considered a novel inflammatory marker. Recently studies are ongoing for objective and easy markers (1)

Objectives: In this study, we aimed to identify the possible relationship between NRL and clinical characteristics inn patients with systemic sclerosis (SSc)

Methods: Our study is based on a retrospective analysis. We collected in a data base clinic and epidemiological characteristic of SSc patients Fifty-two patients (46 female; 10 subset diffuse) with SSc were enrolled consecutively for analyser the correlations. We considered the correlation with NRL and skin core, ulcers, pitting scars, gastro-intestinal events, fibrosis on HTCR, respiratory parameters (FVC, DLCO), PAPs, diastolic abnormalities, capillaroscopy alterations and activity index (2). Student's ttest was used for comparison averages, correlation among variables were assessed by Sperman's correlation testing.

Results: sociodemographic and clinical characteristic were reported in table 1. The correlation analysis statistically significant is summarized in table 2: NLR vs skin score, DLCO, PAPs, and activity index. The correlation analysis between NLR and presence of ulcers and pitting scars was considered not quite significant. There were no correlations between other parameters and NLR.

Conclusion: NLR values correlated negatively with DLCO value, and positively with PAP value, skin score and activity index NLR level may serve as inflammatory marker in patients with SSc.

\section{REFERENCES}

[1] Absenger G. et al. Br J Cancer 2013; 109:395

[2] Valentini G. et al. Ann Rheum Dids 2001; 60:592

Table 1. Sociodemographic and clinical characteristics

\begin{tabular}{lc}
\hline & Patients $\mathrm{n}=52$ \\
\hline Age (years) mean \pm sd & $53.58 \pm 13.99$ \\
Sex $(\mathrm{M} / \mathrm{F})$ & $6 / 46$ \\
Disease duration (years) mean \pm sd & $8.68 \pm 9.6$ \\
WBC count $(\mathrm{K} / \mu \mathrm{L})$ mean $\pm \mathrm{sd}$ & $6748 \pm 2302$ \\
NLR, mean \pm sd & $2398 \pm 1290$ \\
Skin score, mean \pm sd & $3.94 \pm 6.26$ \\
DLCO of predict, mean \pm sd & $71.4 \pm 23.4$ \\
PAPs mmHg, mean $\pm s d$ & $19.9 \pm 19.1$ \\
Ulcers (yes/no) & $5 / 47$ \\
Pitting scars (yes/no) & $18 / 34$ \\
Cpillaroscopy alterations, normal/early/active/late & $6 / 17 / 17 / 12$ \\
Activity index, mean $\pm s d$ & $1.86 \pm 1.48$ \\
\hline
\end{tabular}

Tabel 2. Correlation analysis between NLR and skin score, DLCO, PAPs, activity index

\begin{tabular}{cccccc}
\hline & & $\begin{array}{c}\text { Skin } \\
\text { score }\end{array}$ & DLCO & PAPs & $\begin{array}{c}\text { Activity } \\
\text { index }\end{array}$ \\
\hline NLR & $\begin{array}{c}r \\
\text { value } \\
p\end{array}$ & 0.28 & -0.30 & 0.29 & 0.28 \\
& $\begin{array}{l}p \\
\text { value }\end{array}$ & 0.045 & 0.035 & 0.033 & 0.042 \\
& & & & \\
\hline
\end{tabular}

Disclosure of Interests: None declared

DOI: 10.1136/annrheumdis-2019-eular.3733 